\title{
Characterization of D-cyclin proteins in hematolymphoid neoplasms: lack of specificity of cyclin-D2 and D3 expression in lymphoma subtypes
}

Ryan A Metcalf ${ }^{1}$, Shuchun Zhao ${ }^{1}$, Matthew W Anderson ${ }^{1}$, Zhi Shun Lu ${ }^{1}$, Ilana Galperin ${ }^{1}$, Robert J Marinelli ${ }^{2}$, Athena M Cherry ${ }^{1}$, Izidore S Lossos ${ }^{3}$ and Yasodha Natkunam ${ }^{1}$

${ }^{1}$ Department of Pathology, Stanford University School of Medicine, Stanford, CA, USA; ${ }^{2}$ Department of Biochemistry, Stanford University School of Medicine, Stanford, CA, USA and ${ }^{3}$ Department of Medicine, Division of Hematology-Oncology and Molecular and Cellular Pharmacology, Sylvester Cancer Center, University of Miami, Miami, FL, USA

D-cyclin proteins play a central role in cell-cycle regulation and are involved in the pathogenesis of lymphomas. In mantle-cell lymphoma, the $t(11 ; 14)$ translocation leads to overexpression of cyclin-D1, in addition to which cyclin-D1-negative mantle-cell lymphoma that overexpress cyclin-D2 or D3 have also been described. Although cyclin-D2 and D3 have been implicated in the prognosis of specific lymphoma subtypes, a thorough characterization of $D$-cyclin protein expression in human hematolymphoid neoplasia has not been reported. To evaluate the tissue expression patterns of D-cyclins, particularly D2 and D3, in normal and neoplastic hematolymphoid tissues, we optimized the commercially available antibodies for D-cyclins for use on paraffinembedded tissue and stained tissue microarrays of over 700 patient samples. Our results show that cyclin-D2 and D3 proteins are expressed in many more lymphoma subtypes than cyclin-D1. Cyclin-D1, D2 and D3 were expressed in 100, 22 and $6 \%$ of mantle-cell lymphomas and 2, 49 and $20 \%$ of diffuse large B-cell lymphomas. Fluorescence in situ hybridization studies confirmed the presence of the CCND1/IGH translocation in the majority of mantle-cell lymphoma, but not in diffuse large B-cell lymphoma that expressed cyclin-D1 protein. In addition, a subset of follicular, marginal zone, lymphoplasmacytic, lymphoblastic, classical Hodgkin, mature T-cell and natural killer cell lymphomas and acute myeloid leukemias also expressed cyclin-D2 and D3. These data support the hypothesis that dysregulation of cell-cycle control by D-cyclins contribute to the pathogenesis of hematolymphoid neoplasia, and suggest a potential role for these proteins in the prognostic and therapeutic aspects of these diseases. For diagnostic purposes, however, the expression of D-cyclin proteins should be interpreted with caution in the subclassification of lymphoma types.

Modern Pathology (2010) 23, 420-433; doi:10.1038/modpathol.2009.173; published online 8 January 2010

Keywords: cyclin-D2; cyclin-D3; CCND2; CCND3; diffuse large B-cell lymphoma; tissue microarray

Cyclins are an evolutionarily conserved family of proteins that play an important role in the regulation of the cell cycle by binding to cyclin-dependent kinases. They are synthesized and destroyed in a precise manner and this periodicity enables

Correspondence: Dr Y Natkunam, MD, PhD, Department of Pathology, L235, Stanford University School of Medicine, 300 Pasteur Drive, Stanford, CA 94305, USA.

E-mail: yaso@stanford.edu

Received 20 July 2009; revised and accepted 18 August 2009; published online 8 January 2010 specific cyclin-dependent kinase-cyclin complexes to facilitate the sequential events that take place during cell-cycle progression. ${ }^{1}$ D-cyclins (D1, D2 and D3) are structurally and functionally similar proteins that bind to and activate cyclin-dependent kinase- 4 and 6 during the $\mathrm{G}_{1}$ phase of the cell cycle as the cell prepares to initiate DNA synthesis. ${ }^{1-3}$ In mammalian cells, deregulation of these proteins leads to significantly increased cell proliferation and turnover.

Overexpression of D-cyclins has been implicated in the pathogenesis of lymphomas. ${ }^{4}$ Translocation 
$\mathrm{t}(11 ; 14)(\mathrm{q} 13 ; \mathrm{q} 32)$ at the cyclin-D1 locus is the hallmark of mantle-cell lymphoma. ${ }^{5,6}$ Although cyclinD1 is overexpressed in the majority of mantle-cell lymphoma, recent studies using gene expression profiling have identified cyclin-D1-negative mantlecell lymphoma that overexpress cyclin-D2 or D3. ${ }^{7}$ Additional studies have revealed specific translocations involving the CCND2 and CCND3 loci that lead to overexpression of their cognate cyclin-D2 or D3 proteins in cyclin-D1-negative mantle-cell lymphoma. ${ }^{8-10}$ In a multivariate model correlating the expression of six genes (as measured by quantitative RT-PCR) that predicts outcome in patients with diffuse large B-cell lymphoma, we had previously identified CCND2 as a marker of poor prognosis. ${ }^{11,12}$ Overexpression of the cyclin-D2 protein was also found to be an independent predictor of inferior 5 -year overall survival in diffuse large B-cell lymphoma patients. ${ }^{13}$ The overexpression of cyclin-D3 protein in indolent lymphomas has been associated with adverse clinical features, including a highintermediate or high-risk International Prognostic Index, and poor overall and relapse-free survival. ${ }^{14}$

The role of D-cyclins in hematolymphoid neoplasms is becoming increasingly recognized. Although the tissue distribution pattern of cyclinD1 protein has been previously documented, there are limited data on cyclin-D2 and D3 proteins. As cyclin-D2 and D3 immunostaining is likely to be used for differentiating cyclin-D1-negative mantlecell lymphoma from other lymphoma subtypes, and cyclin-D2 may have clinical utility as a prognostic marker in diffuse large B-cell lymphoma, it is of importance to know their tissue distribution pattern and reactivity in hematopoietic neoplasms. Therefore, our aim in this study was to characterize the expression profiles of D-cyclin proteins, particularly cyclin-D2 and D3, in a wide variety of normal and neoplastic tissue samples obtained from formalinfixed and paraffin-embedded patient biopsies. We document the differential expression patterns of D-cyclins and explore the utility of immunohistogic staining for D-cyclins in the diagnostic setting.

\section{Materials and methods}

\section{Tissue Samples}

Formalin-fixed, paraffin-embedded tissue samples of normal and neoplastic hematolymphoid cases were obtained from the archives of the Department of Pathology, Stanford University Medical Center (Stanford, CA). Institutional Review Board (IRB) approval was obtained for these studies. The cases were studied by immunohistochemistry and fluorescence in situ hybridization (FISH) on tissue microarrays (TMAs), and on whole sections wherever detailed evaluation was deemed necessary. For expression in normal hematopoietic tissues, 3-5 examples each of tonsil, lymph node, thymus, spleen and bone marrow core biopsies were used. Hematolymphoid neoplasias were classified according to the current WHO scheme. ${ }^{6}$ TMA construction has been described previously. ${ }^{15,16}$

To screen for the expression of D-cyclin proteins in non-hematopoietic tissue, TMAs containing 100 samples of various tissues (neoplastic and nonneoplastic) were used. Two each of the following normal tissue samples were analyzed: adrenal, bladder, brain, breast, colon, kidney, liver, lung, muscle (heart and skeletal), ovary, pancreas, prostate, stomach, testis, thyroid and uterus. Neoplastic tissue samples included carcinomas of the adrenal cortex (2), bladder (2), breast (8), colon (6), head and neck squamous cell (2), liver (four hepatocellular and four cholangiocarcinoma), lung (four adenocarcinoma and four squamous cell carcinoma), ovary (6), parathyroid (4), prostate (3), stomach (2), thyroid (2) and uterus (4), as well as glioblastoma multiforme (2), seminoma (2) and soft-tissue sarcomas (13).

\section{Immunohistochemistry}

Serial $4 \mu \mathrm{m}$-thick sections from paraffin-embedded whole-tissue sections and TMA blocks were deparaffinized in xylene and hydrated in a series of graded alcohols. Antibodies directed against D-cyclins were used at a dilution of 1:100 for anticyclin-D1 (clone SP4; Thermo Fisher Scientific, Fremont, CA, USA), 1:400 for anti-cyclin-D2 (clone M-20; Santa Cruz Biotechnology, Santa Cruz, CA, USA) and 1:30 for anti-cyclin-D3 (clone DCS-22; Santa Cruz Biotechnology, Santa Cruz, CA, USA). Dako citrate retrieval and detection were performed by the Dako Envision method (Dako Corporation, Carpentaria, CA, USA).

Staining for cyclin-D2 and D3 proteins was optimized on normal paraffin-embedded tonsil sections. Cyclin-D2 staining was primarily localized to the nucleus, although a combination of nuclear and cytoplasmic staining was frequently seen in positive cell types. Weak cytoplasmic staining without corresponding nuclear staining was not considered positive. Cyclin-D3 staining was crisply localized to the nucleus and resembled cyclin-D1 staining. A cut-off of staining in greater than $20 \%$ of lymphoma cells was assigned a positive score. This cut-off was based on the need for using a nonambiguous threshold for scoring TMAs and does not reflect the differences in staining intensity between normal and neoplastic tissue or among different diagnoses. The cut-off was chosen before correlation with other immunohistological markers. The distinction between positive and negative cases was relatively straightforward using standard light microscopy. Two pathologists (RA Metcalf and Y Natkunam) independently scored all the cases and any discrepancies were resolved by re-scoring over a double-headed microscope. 
Double-immunohistochemical labeling for both cyclin-D2 (1:60 dilution) and cyclin-D3 (1:30 dilution) was performed using the Dako Envision G2 double staining system (Dako, Carpentaria, CA, USA). Heat-induced antigen retrieval was performed using the Decloaking Chamber (Biocare Medical, Concord, CA, USA) in Tris/EDTA buffer (50 mM TRIS/20 mM EDTA, pH 9.0). Antibodies directed against the following markers were used in combination with cyclin-D2 or cyclin-D3: CD20 (1:1000 dilution; Dako), CD3 (1:100 dilution; Cell Marque Corp., Rocklin, CA, USA), CD34 (1:10 dilution; BD Biosciences, San Jose, CA, USA), myeloperoxidase (1:8000 dilution; Dako, Carpentaria, CA, USA) and glychophorin (1:100 dilution; Dako).

\section{Fluorescence In Situ Hybridization}

Formalin-fixed, paraffin-embedded thin tissue sections were pretreated by standard protocol using the VP2000 slide pretreatment instrument (Abbott Molecular, Abbott Park, IL, USA). Briefly, slides were deparaffinized with CitroSolv (Fisher Scientific, Pittsburg, PA, USA), digested with a $10 \%$ pepsin solution at $37^{\circ} \mathrm{C}$ (Protease I, VP2000 Protease Buffer; Abbott Molecular), pretreated with a sodium thiocyanate solution at $80^{\circ} \mathrm{C}$ (VP2000 Pretreatment Solution; Abbott Molecular), re-fixed in 10\% buffered formalin and dehydrated in an ethanol series.

Dried, dehydrated slides were denatured with a Vysis HYBrite instrument at $73^{\circ} \mathrm{C}$ for $6 \mathrm{~min}$ and hybridized for $48 \mathrm{~h}$ at $37^{\circ} \mathrm{C}$ with the CCND1(BCL1)/ IGH dual-color, dual-fusion probe (Abbot Molecular). Slides were washed with $2 \times$ SSC/0.3\% NP-40 at $73^{\circ} \mathrm{C}$ for $2 \mathrm{~min}$, counterstained with DAPI and analyzed with an Olympus BX51 microscope equipped with a $\times 100$ oil-immersion objective, appropriate fluorescent filters and the CytoVision imaging software (Applied Imaging, San Jose, CA, USA).

Two hundred interphase nuclei were analyzed for each specimen. Nuclei demonstrating single CCND1 (red) and $I G H$ (green) signals, and two CCND1/IGH fusion signals (yellow) were scored as positive for $C C N D 1 / I G H$-gene rearrangement. Nuclei with two $C C N D 1$, two IGH signals and no fusion signals were scored as negative. Specimens with greater than $30 \%$ of nuclei demonstrating CCND1/IGH fusion signal patterns were considered positive for CCND1/ $I G H$-gene rearrangement.

\section{TMA Data Analysis and Visualization}

The stained lymphoma TMA slides were scanned and stored as high-resolution images using an automated scanner (Bacus Laboratories Inc., Slide Scanner (BLISS); http://www.bacuslabs.com). The 'Deconvoluter' algorithm (custom WBS macro, Excel; Microsoft) with appropriate layout for use in the Cluster software was used for hierarchical clustering to integrate all immunohistological staining results, as previously described (http://genomewww.stanford.edu/TMA/). ${ }^{17}$ A total of 2784 TMA images generated from cyclin-D2 and D3 staining are displayed on the following freely accessible website: http://tma.stanford.edu/tma_portal/cyclins.

\section{Results}

Immunohistochemistry for cyclin-D1 on normal hematopoietic and non-hematopoietic tissues was not performed as part of the current study, as this marker has been in routine use for a number of years and its tissue distribution pattern is well documented. For purposes of comparison, cyclin-D1 expression was studied only in hematopoietic tumors (Table 1), and detailed characterization of the cyclin-D2 and D3 proteins is presented. All three D-cyclins were expressed in endothelial cells, which allowed for excellent internal positive controls for comparisons among the three stains in paraffin tissue biopsies and TMA cores.

\section{Cyclin-D2 Protein shows Widespread Expression among Normal Tissues and in Hematopoietic and Non-Hematopoietic Neoplasms}

Cyclin-D2 staining in normal tonsil and lymph node tissue showed a range of staining from weak to strong in a subset of cells within germinal centers, mantle and marginal zones, and in the paracortex (Figure 1a and b). Plasma cells typically showed cytoplasmic localization of the stain, with only weak nuclear staining. In tonsils, a subset of intraepithelial lymphocytes also showed staining. Double immunohistochemical labeling of tonsil sections with CD20 and CD3 showed that a proportion of both B- and T-cells stain for this marker (Figure 1c and $\mathrm{d}$ ). In normal thymi, there was staining in scattered cortical and medullary cells (Figure 1e). Double immunohistochemical labeling of thymic sections showed a staining pattern similar to that seen in tonsils, with colocalization of the stain in a proportion of CD20-positive B-cells and CD3-positive T-cells. In normal spleen, staining for cyclin-D2 was confined to scattered lymphoid cells and plasma cells, but was absent from splenic marginal zone cells within the white pulp (Figure 1f). In addition, staining was prominent in endothelial cells (splenic littoral cells). Sections of normal bone marrow showed cyclin-D2 staining in scattered lymphoid cells; however, the majority of myeloid and erythroid precursors, and megakaryocytes lacked staining, except for weak staining in occasional myeloid precursors (Figure 1g). Double labeling of cyclin-D2 with myeloperoxidase (specific for myeloid and monocytic lineages), glycophorin (specific for erythroid lineage) and CD34 (immature blasts) did not show significant coexpression (data not shown). 
Table 1 Summary of immunohistochemistry for D-cyclin expression

\begin{tabular}{|c|c|c|c|}
\hline Lymphoma subtype & Cyclin-D1 & Cyclin-D2 & Cyclin-D3 \\
\hline Diffuse large B-cell lymphoma, NOS) & $4 / 204(2)$ & 95/194 (49) & $44 / 220(20)$ \\
\hline Follicular lymphoma, grade 1 and 2 & $0 / 87(0)$ & $24 / 79(30)$ & $6 / 93(6)$ \\
\hline Follicular lymphoma, grade 3 & $0 / 69(0)$ & $21 / 61(34)$ & $10 / 71(14)$ \\
\hline Extranodal marginal-zone lymphoma & $0 / 21(0)$ & $4 / 17(24)$ & $0 / 24(0)$ \\
\hline Nodal marginal-zone lymphoma & $0 / 5(0)$ & $1 / 4(25)$ & $1 / 5(20)$ \\
\hline Splenic marginal-zone lymphoma & $0 / 5(0)$ & $0 / 4(0)$ & $0 / 5(0)$ \\
\hline Mantle-cell lymphoma & $18 / 18(100)$ & $3 / 18(22)$ & $1 / 18(6)$ \\
\hline Mantle-cell lymphoma, blastoid variant & $5 / 5(100)$ & $1 / 5(20)$ & $0 / 5(0)$ \\
\hline Chronic lymphocytic leukemia/SLL & $0 / 36(0)$ & $11 / 36(31)$ & $2 / 38(5)$ \\
\hline Lymphoplasmacytic lymphoma & $0 / 5(0)$ & $3 / 5(60)$ & $0 / 5(0)$ \\
\hline Plasma-cell myeloma & $0 / 2(0)$ & $0 / 2(0)$ & $1 / 2(50)$ \\
\hline Burkitt lymphoma & $0 / 3(0)^{\mathrm{a}}$ & $1 / 2(50)$ & $1 / 3(33)$ \\
\hline B-lymphoblastic lymphoma/leukemia & $0 / 7(0)$ & $4 / 7(57)$ & $3 / 14(21)$ \\
\hline T-lymphoblastic lymphoma & $0 / 12(0)$ & $10 / 11(91)$ & $3 / 12(25)$ \\
\hline Peripheral T-cell lymphoma, NOS & $0 / 18(0)^{\mathrm{a}}$ & $10 / 18(56)$ & $1 / 20(5)$ \\
\hline Adult T-cell lymphoma & $0 / 1(0)$ & $0 / 1(0)$ & $0 / 1(0)$ \\
\hline Angioimmunoblastic T-cell lymphoma & $0 / 3(0)$ & $1 / 3(33)$ & $0 / 3(0)$ \\
\hline Anaplastic large-cell lymphoma, ALK+ & $0 / 7(0)$ & $3 / 5(60)$ & $2 / 8(25)$ \\
\hline Extranodal NK/T-cell lymphoma, nasal type & ND & ND & $3 / 63(5)$ \\
\hline Classical Hodgkin lymphoma & ND & $76 / 101(75)$ & $21 / 125$ (17) \\
\hline Acute myeloid leukemia & ND & $6 / 6(100)$ & $6 / 6(100)$ \\
\hline
\end{tabular}

The proportion of cases of each diagnostic category that stained positive is shown in parentheses.

${ }^{\mathrm{a}}$ Occasional cells $(<20 \%$ of lymphoma cells) showed staining in one Burkitt and two peripheral T-cell lymphomas (NOS).

Among hematopoietic neoplasms, staining for cyclin-D2 was present in nearly half of diffuse large B-cell lymphomas (95/194, 49\%) (Figure 2a), along with a significant proportion of all histological grades of follicular lymphomas $(45 / 140,32 \%)$ (Figure 2b), marginal zone lymphomas (5/25, 25\%) (Figure 2c), mantle-cell lymphomas (typical 3/18, $17 \%$ and blastoid variant $1 / 5,20 \%$ ), lymphoplasmacytic lymphomas $(3 / 5,60 \%)$, chronic lymphocytic leukemia/small lymphocytic lymphomas (11/36, $31 \%$ ) (Figure 2d), B-lymphoblastic lymphomas (4/7, 57\%), T-lymphoblastic lymphomas (10/11, 91\%), peripheral T-cell lymphomas (10/18, 56\%) (Figure 2f), anaplastic large-cell lymphomas (ALCLs) (3/5, $60 \%$ ) and classical Hodgkin lymphomas (76/101, $75 \%$ ) (Figure 2e). All six cases of acute myeloid leukemia showed cyclin-D2 staining in the blast population. These cases included two acute myeloid leukemias, not otherwise specified, two acute myeloid leukemias with associated multi-lineage dysplasias, one acute myeloid leukemia with a 11 q23 deletion and one acute myeloid leukemia arising as a result of blast transformation from $t(9 ; 22)$-positive chronic myeloid leukemia (Table 1).

Seventy-three samples of non-hematolymphoid tissues from various adult organs and corresponding neoplasms were stained for cyclin-D2. The majority of the cases $(53 / 73,73 \%)$ showed nuclear staining or a combination of nuclear and cytoplasmic staining for cyclin-D2 (Table 2). Only staining in the relevant lesional cells or tissue compartment was scored positive; in the case of malignancies, the neoplastic infiltrate was evaluated. Cyclin-D2 staining was present in endothelial cells in most of the tissue cores and full sections examined.

\section{Cyclin-D3 Protein shows a Restricted Pattern of Expression among Normal Tissues and in Hematopoietic and Non-Hematopoietic Neoplasms}

Cyclin-D3 staining in normal tonsil and lymph node tissue showed intense and crisply localized nuclear staining in a subset of lymphoid cells within germinal centers and in the paracortex; only rare cells were appreciated within the mantle and marginal zones (Figure 3a). The overall distribution of the stained cells was similar to that of cyclin-D2 staining, but fewer cells stained for cyclin-D3 than for the cyclin-D2 protein within each compartment. Occasional plasma cells showed a combination of nuclear (weak) and cytoplasmic (strong) staining. In tonsils, a few intraepithelial lymphocytes also showed staining. Double immunohistochemical labeling of tonsil sections with CD20 and CD3 showed that the vast majority of $\mathrm{B}$ - and T-cells lacked cyclin-D3 staining; however, cyclin-D3 staining was seen in occasional B- and T-cells (Figure 3b and c). In normal thymi, there was staining in scattered cortical and medullary cells in a pattern similar to that in cyclin-D2 staining (Figure 3d). Double immunohistochemical labeling of thymic sections again showed colocalization of cyclin-D3 staining in subsets of CD20-positive B-cells and CD3-positive T-cells. In normal spleen, staining for cyclin-D3 was confined to scattered lymphoid cells and plasma cells in the red pulp and endothelial cells; lymphoid cells of the splenic marginal zone 

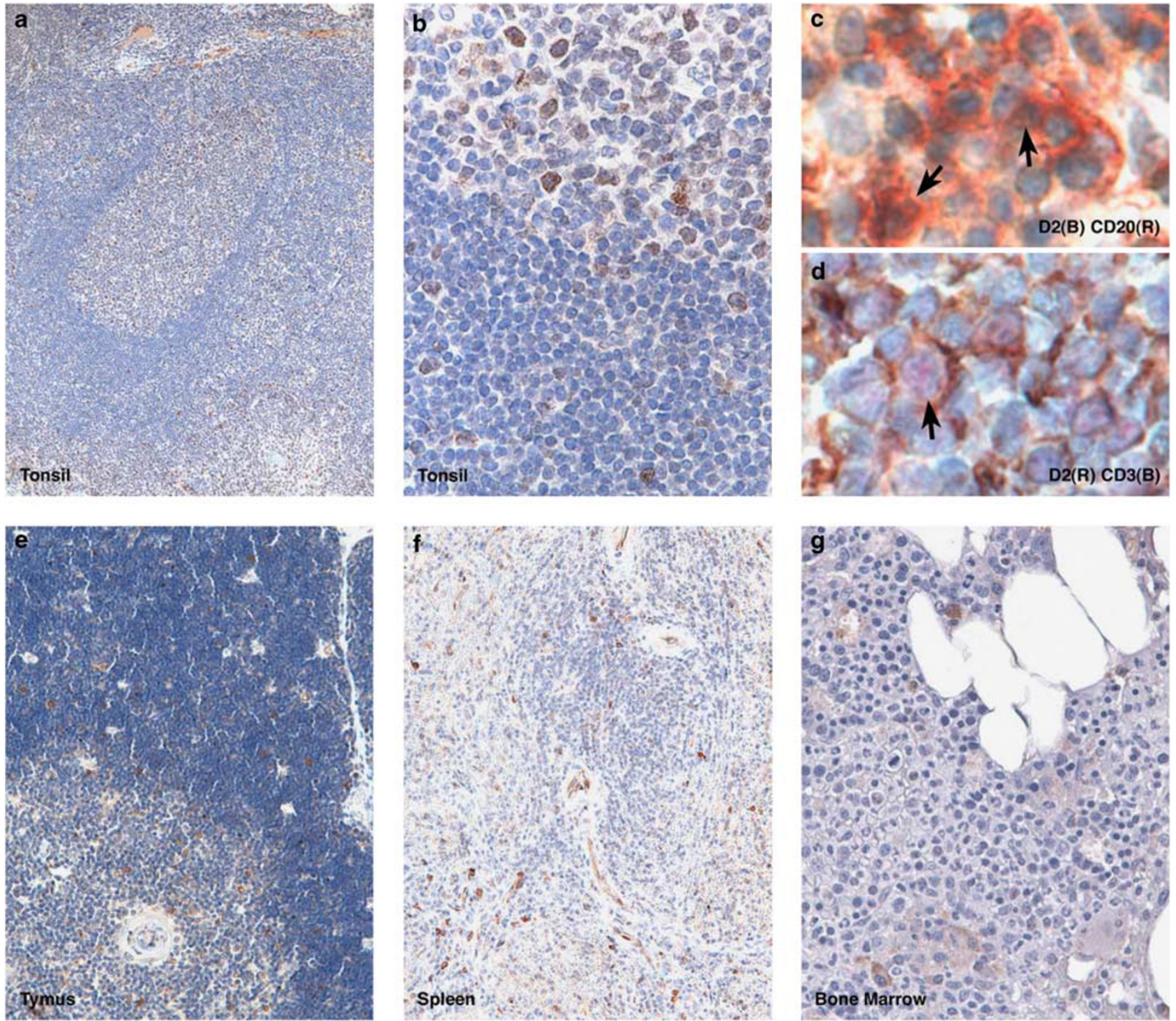

Figure 1 Cyclin-D2 expression in normal hematopoietic tissue. Cyclin-D2 staining is found in a subset of cells in the germinal center, mantle and marginal zones and in the paracortex of a normal tonsil (a, b). Double immunohistochemical labeling for cyclin-D2 (brown) and CD20 (red) shows colocalization of staining in a subset of B-cells (arrows, c). Double immunohistochemical labeling for cyclin-D2 (red) and CD3 (brown) shows colocalization of staining in a subset of T-cells (arrow, d). Scattered cells in the cortex and medulla of the normal thymus show cyclin-D2-positive cells (e). The normal spleen shows staining in scattered lymphoid cells in the red and white pulp and in endothelial cells, but is lacking in splenic marginal zones (f). The normal bone marrow shows staining in scattered lymphoid and plasma cells, but is not found in the majority of erythroid or myeloid precursors or megakaryocytes (g).

lacked staining (Figure 3e). Sections of normal bone marrow showed prominent cyclin-D3 staining in megakaryocytes (nuclear and cytoplasmic) and in a subset of erythroid precursors, which was confirmed by double immunohistochemical labeling for glycophorin (Figure 3f, inset). Myeloid precursors and blasts lacked staining for cyclin-D3, which was confirmed by double labeling for myeloperoxidase and CD34 (data not shown).

Cyclin-D3 immunostaining highlighted a minority of cases of nearly all subtypes of hematopoietic tumors (Table 1). In contrast to cyclin-D2, cyclin-D3 staining was found in a smaller proportion of diffuse large B-cell lymphomas (44/220, 20\%) (Figure 4a).
Cyclin-D3 staining was seen in a small number of all grades of follicular lymphoma (Figure 4b), although the proportion of cases that stained positive increased with the grade of the tumor: grade $1(1 / 37$, $3 \%)$, grade $2(5 / 55,9 \%)$ and grade $3(10 / 72,14 \%)$. A small minority of marginal-zone lymphomas (2/35, $6 \%$ ) (Figure 4c), mantle-cell lymphomas (typical $1 / 18,6 \%$ and blastoid variant $0 / 5,0 \%$ ), chronic lymphocytic leukemia/small lymphocytic lymphomas $(2 / 38,5 \%)$ (Figure $4 d$ ), peripheral T-cell lymphomas $(1 / 20,5 \%)$ (Figure $4 \mathrm{f}$ ) and extranodal NK/ T-cell lymphomas (nasal type) $(4 / 83,5 \%)$ were positive. Additionally, a slightly higher proportion of classical Hodgkin lymphomas (21/125, 17\%) 

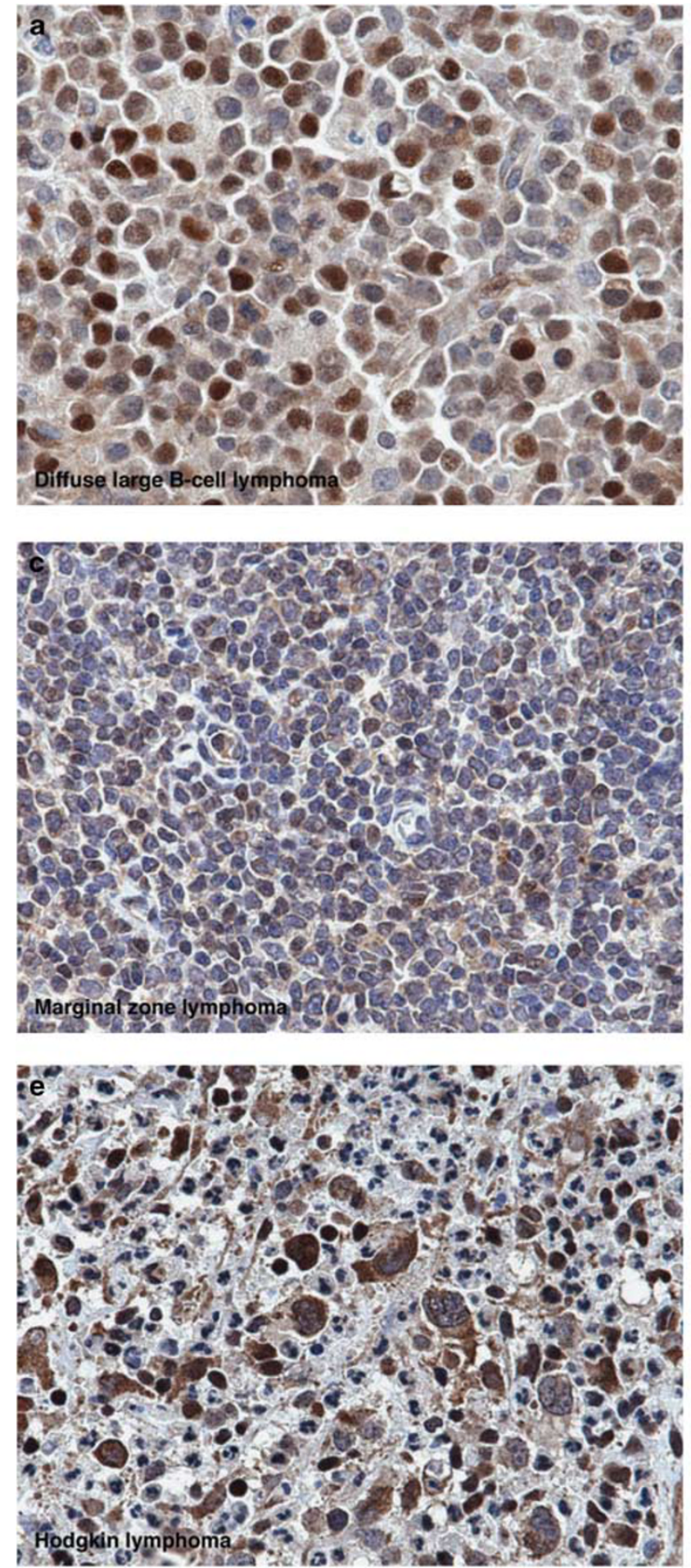
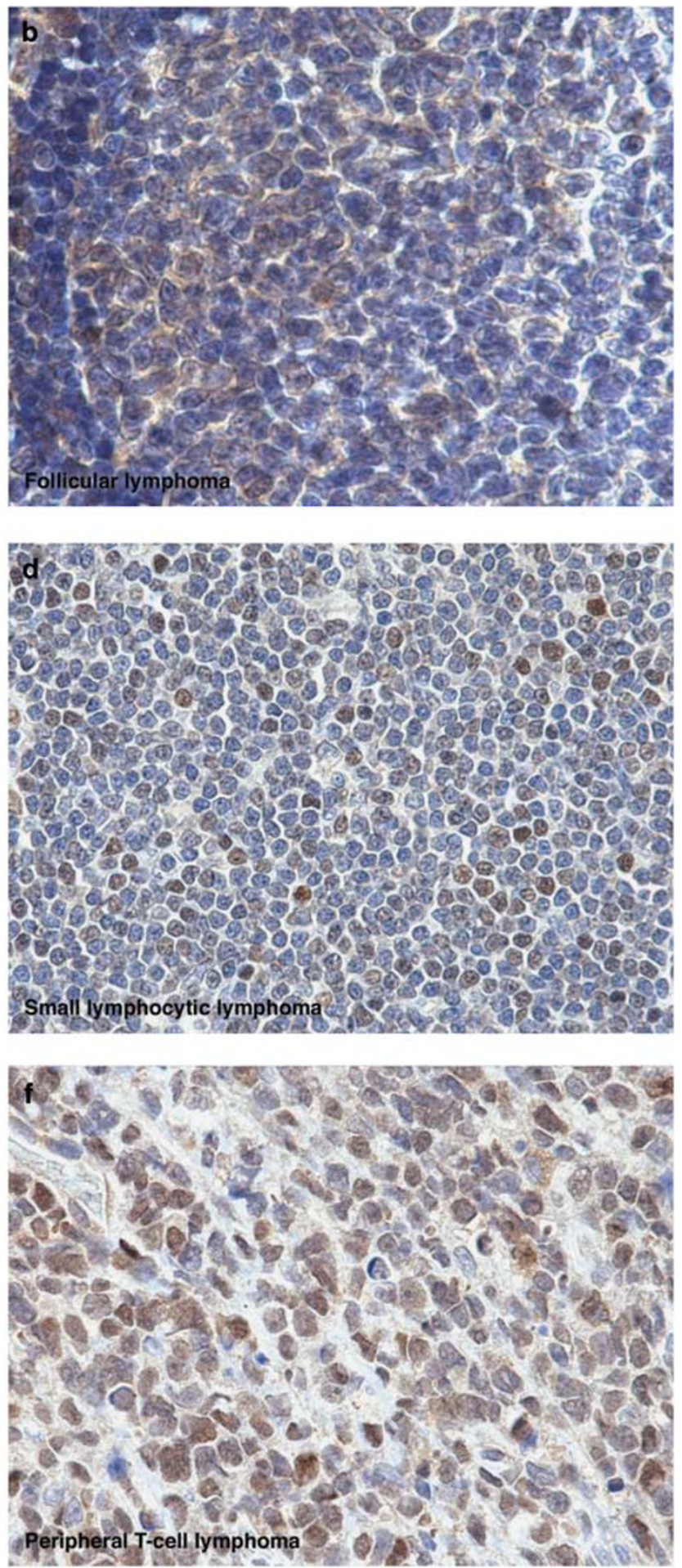

Figure 2 Cyclin-D2 expression in hematopoietic neoplasia. Cyclin-D2 staining is shown in examples of diffuse large B-cell lymphoma (a), follicular lymphoma (b), marginal-zone lymphoma (c), small lymphocytic lymphoma (d), classical Hodgkin lymphoma (e) and peripheral T-cell lymphoma (f). In all the cases, the staining is primarily localized to the nucleus, although associated cytoplasmic staining is also seen in some instances.

(Figure 4e), B-lymphoblastic lymphomas (3/14, $21 \%)$, T-lymphoblastic lymphomas $(3 / 12,25 \%)$ and ALCLs (2/8, 25\%) expressed cyclin-D3. All six cases of acute myeloid leukemia showed cyclin-D3 staining in a small subset of blasts, although four of the six cases showed expression in only rare clusters of cells. The one case of megakaryoblastic leukemia (acute myeloid leukemia, not otherwise specified or FrenchAmerican-British classification, subtype M7) showed staining in the atypical megakaryoblasts. 
Table 2 Summary of immunohistochemistry for cyclin-D2 and D3 expression in non-hematopoietic tissue and tumor types

\begin{tabular}{|c|c|c|}
\hline Tissue/tumor & Cyclin-D2 & Cyclin-D3 \\
\hline Adrenal (normal) & $1 / 1$ & $0 / 1$ \\
\hline Adrenocortical carcinoma & $0 / 1$ & $0 / 1$ \\
\hline Bladder mucosa (normal) & $1 / 1$ & $0 / 1$ \\
\hline Bladder, urothelial carcinoma & $1 / 2$ & $0 / 1$ \\
\hline Brain, normal & $1 / 1$ & $0 / 1$ \\
\hline Brain, GBM & $2 / 2$ & $0 / 2$ \\
\hline Breast, normal & $0 / 1$ & $0 / 1$ \\
\hline Breast carcinoma & $4 / 13$ & $2 / 13$ \\
\hline Colon, normal & $2 / 2$ & $0 / 1$ \\
\hline Colon, adenocarcinoma & $2 / 2$ & $0 / 3$ \\
\hline ENT, squamous cell carcinoma & $1 / 1$ & $1 / 1$ \\
\hline Heart, normal & $1 / 1$ & $0 / 1$ \\
\hline Kidney, normal & $2 / 2$ & $1 / 1$ \\
\hline Kidney, renal-cell carcinoma & $2 / 2$ & $0 / 2$ \\
\hline Liver, normal & $1 / 1$ & $1 / 1$ \\
\hline Liver, hepatocellular carcinoma & $2 / 2$ & $0 / 2$ \\
\hline Lung, normal & $1 / 2$ & $0 / 1$ \\
\hline Lung, carcinoma & $2 / 2$ & $2 / 2$ \\
\hline Ovary, normal & $1 / 1$ & $0 / 1$ \\
\hline Ovary, carcinoma & $0 / 2$ & $0 / 3$ \\
\hline Pancreas, normal & $1 / 1$ & $0 / 1$ \\
\hline Pancreas, adenocarcinoma & $0 / 2$ & $0 / 1$ \\
\hline Parathyroid, normal & $3 / 3$ & $0 / 3$ \\
\hline Prostate, normal & $1 / 1$ & $0 / 1$ \\
\hline Prostate, carcinoma & $3 / 3$ & $0 / 3$ \\
\hline Salivary gland, normal & $1 / 1$ & $0 / 1$ \\
\hline Skin, melanoma & $1 / 1$ & $1 / 1$ \\
\hline Soft tissue fibromatosis & $1 / 1$ & $0 / 1$ \\
\hline Soft tissue sarcomas & $6 / 6$ & $2 / 6$ \\
\hline Stomach, normal & $1 / 1$ & $0 / 1$ \\
\hline Stomach, adenocarcinoma & $1 / 1$ & $0 / 1$ \\
\hline Testis, normal & $1 / 1$ & $0 / 1$ \\
\hline Testis, seminoma & $1 / 1$ & $0 / 1$ \\
\hline Thyroid, normal & $1 / 1$ & $0 / 1$ \\
\hline Thyroid, carcinoma & $2 / 3$ & $0 / 3$ \\
\hline Uterus, normal & $2 / 2$ & $0 / 2$ \\
\hline Uterus, endometrial carcinoma & $0 / 2$ & $0 / 2$ \\
\hline Total & $53 / 73(73 \%)$ & $10 / 70(14 \%)$ \\
\hline
\end{tabular}

Seventy samples of non-hematolymphoid tissues from various adult organs and corresponding tumors were stained for cyclin-D3. In contrast to cyclin-D2, only a small minority of cases (10/70, $14 \%$ ) expressed cyclin-D3 and included a ductal carcinoma of the breast, a lobular carcinoma of the breast, a squamous cell carcinoma of the head and neck, a lung squamous cell carcinoma, a lung adenocarcinoma, a melanoma, a gastrointestinal stromal tumor and a malignant fibrous histiocytoma (Table 2). Of the normal tissues, liver and kidney showed staining for cyclin-D3. As described for cyclin-D2, staining in the relevant lesional cells or tissue compartment was scored positive; in the case of malignancies, the neoplastic infiltrate was evaluated.

\section{Cyclin-D1 (BCL1) Protein Expression is Limited to Mantle-Cell Lymphoma and Rare Diffuse Large B-Cell Lymphoma}

To facilitate comparison between cyclin-D1, D2 and D3 staining across lymphoma subtypes, immuno- histochemistry for cyclin-D1 was performed in the same set of hematopoietic tumors as that used for the study of cyclin-D2 and D3 (Table 1). All 18 cases of typical mantle-cell lymphoma and five cases of blastoid mantle-cell lymphoma showed nuclear staining for cyclin-D1. One mantle-cell lymphoma showed relatively weak staining in comparison with the others; however, the majority of the nuclei in the lymphoma cells showed the presence of cyclin-D1. Four cases of diffuse large B-cell lymphoma (of 204 studied) showed nuclear staining for cyclin-D1 in the majority of tumor cells. In addition, one case of Burkitt lymphoma (1/3) and two cases of peripheral T-cell lymphoma (2/18) showed occasional lymphoma cells with nuclear staining. These latter cases did not meet the threshold defined for a positive score in this study. All remaining lymphoma subtypes lacked staining for cyclin-D1 (Table 1).

Among the 18 typical mantle-cell lymphoma cases, 17 showed strong staining for cyclin-D1 (representative case illustrated in Figure 5a-c), three cases expressed cyclin-D2 and a single case expressed cyclin-D3. The case that was weakly positive for cyclin-D1 showed strong staining for cyclin-D2 (Figure 5d-f). Two of the three cases that stained for cyclin-D2, and the case that stained for cyclin-D3, also harbored the CCND1/IGH translocation as shown by FISH analysis. All five cases of blastoid mantle-cell lymphoma showed strong staining for cyclin-D1, in addition to which one case showed weak expression of cyclin-D2. None of the cases showed staining for all three D-cyclins.

We performed FISH analysis on TMAs and whole sections for the CCND1/IGH translocation to assess whether the cases positive for cyclin-D1 on immunohistochemistry also harbored the translocation. Sixteen of the 18 cases of mantle-cell lymphoma showed the presence of the CCND1/IGH translocation (Figure 6a). However, the translocation was lacking in the two cyclin-D1-positive diffuse large B-cell lymphoma cases that were tested (Figure 6b). Material was not available for the other two diffuse large B-cell lymphoma cases. FISH analysis did not demonstrate the CCND1/IGH translocation in the Burkitt and peripheral T-cell lymphoma cases that showed cyclin-D1 staining in scattered cells. The translocation was also absent in all other hematopoietic tumor types analyzed on our TMA (a total of 477 lymphomas).

\section{Protein Expression Profiles of Cyclin-D2 and D3 in Diffuse Large B-Cell Lymphoma}

In prior studies, CCND2 mRNA and cyclin-D2 protein have been found to correlate with an inferior outcome in patients with diffuse large B-cell lymphoma. ${ }^{11-13}$ The significance of cyclin-D3 expression in diffuse large B-cell lymphoma has not 



Figure 3 Cyclin-D3 expression in normal hematopoietic tissue. Cyclin-D3 staining is found in a subset of cells in the germinal center, and rarely in the mantle and marginal zones and paracortex of a normal tonsil (a). Double immunohistochemical labeling for cyclin-D3 (brown) and CD20 (red) shows colocalization of staining in occasional B-cells (arrows, b). Double immunohistochemical labeling for cyclin-D3 (brown) and CD3 (red) shows colocalization of staining in a subset of T-cells (arrow, c). Scattered cells in the cortex and medulla of the normal thymus show cyclin-D3-positive cells (d). The normal spleen shows staining in scattered lymphoid cells in the red and white pulp and in endothelial cells, but is lacking in splenic marginal zones (e). The normal bone marrow shows staining in scattered lymphoid and plasma cells, megakaryocytes and in a subset of erythroid precursors (f). Double immunohistochemical labeling of erythroid precursors with glycophorin (red) and cyclin-D3 (brown) shows colocalization of staining in erythroid cells (inset and arrows).

been explored previously. Therefore, we compared the relationship of cyclin-D2 and D3 protein expression in 143 cases of diffuse large B-cell lymphoma with which we had previously analyzed the expression of CD10, BCL6, HGAL, LMO2, BCL2 and MUM1/IRF4. ${ }^{15,18}$ Hierarchical cluster analysis of immunohistological data showed that the expression patterns of cyclin-D2 and D3 were closely related to each other and clustered on one branch of the dendrogram, but was distinct from both the germinal-center and non-germinal-center markers (Figure 7).

\section{The Expression of D-Cyclins is Variably Associated with the Degree of Proliferation in Lymphoma Subtypes}

To address whether the expression of D-cyclins was associated with the degree of proliferation in 

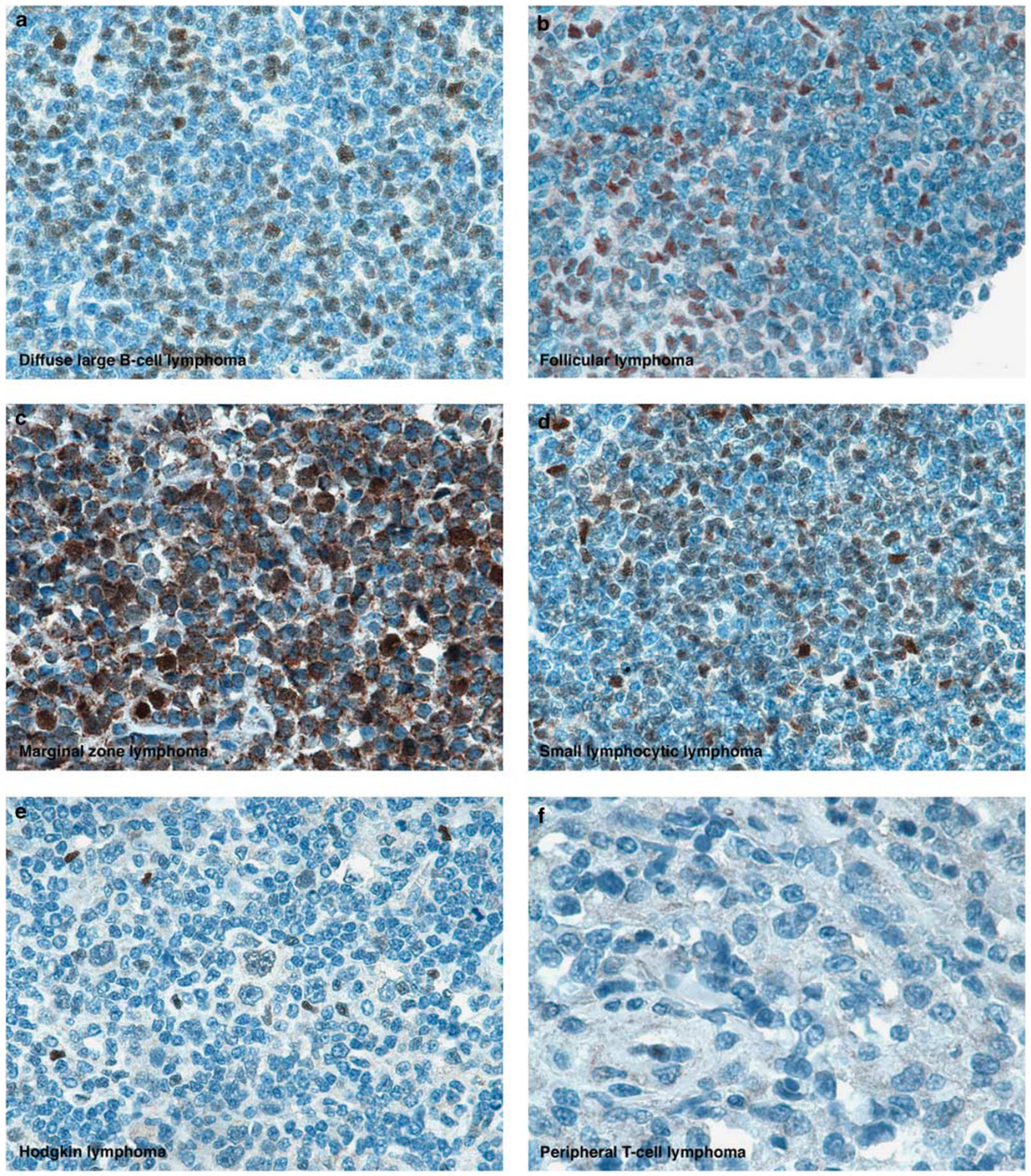

Figure 4 Cyclin-D3 expression in hematopoietic neoplasia. Cyclin-D3 staining is shown in examples of diffuse large B-cell lymphoma (a), follicular lymphoma (b), marginal-zone lymphoma (c), small lymphocytic lymphoma (d), classical Hodgkin lymphoma (e) and peripheral T-cell lymphoma (f). In all the cases, except in the peripheral T-cell lymphoma, the staining is primarily localized to the nucleus, although associated cytoplasmic staining is also seen in some instances. The case of peripheral T-cell lymphoma lacked staining for cyclin-D3.

lymphoma subtypes, we performed Ki-67 staining on the lymphoma TMAs. Data for all four markers (cyclin-D1, D2, D3 and Ki-67) was available on 61 diffuse large B-cell lymphoma cases; we found no specific correlation among D-cyclin expression and proliferation as measured by Ki-67 (Table 3). In addition, in 24 cases of diffuse large B-cell lymphoma that did not express any of the three 

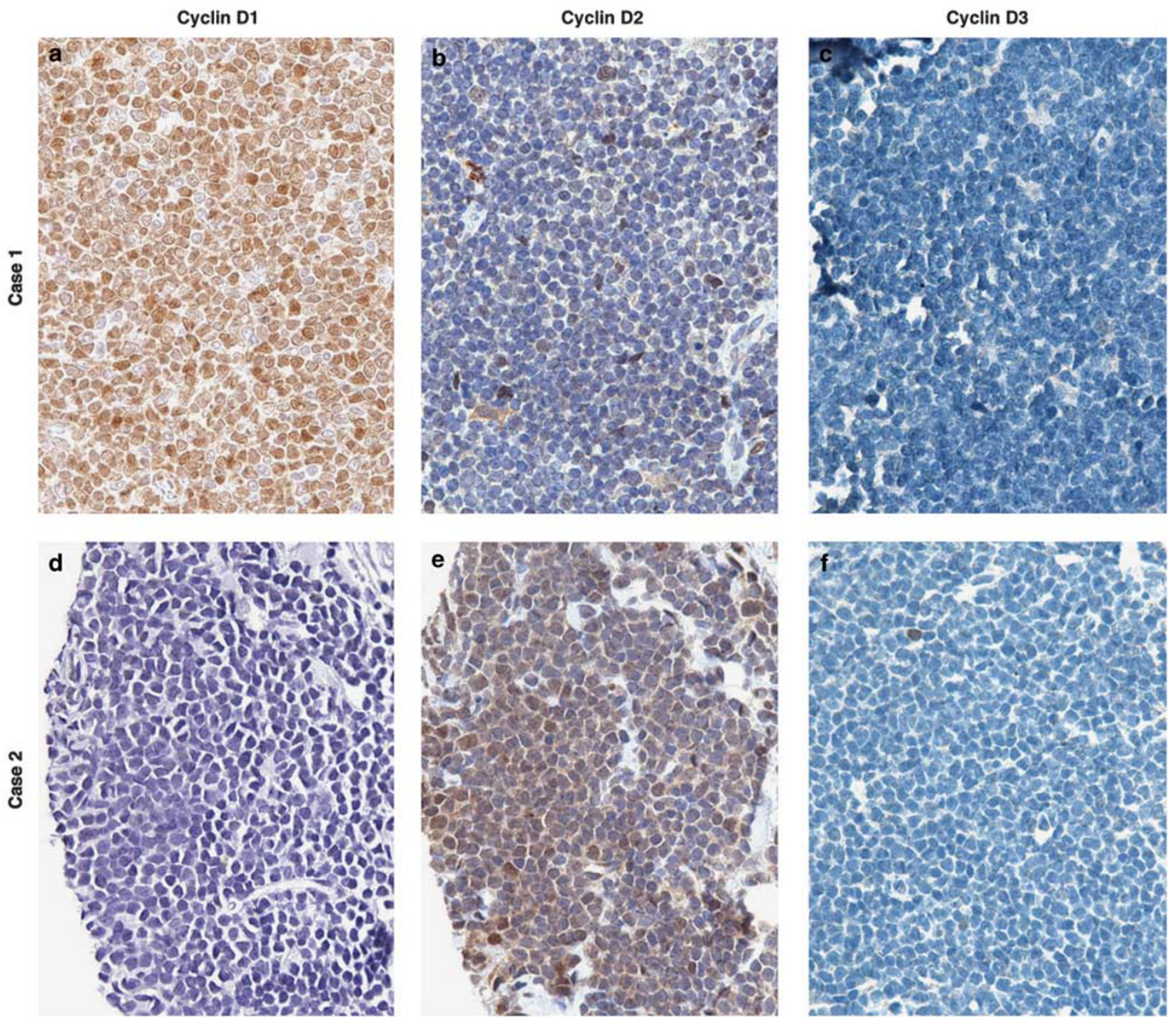

Figure 5 The expression of D-cyclins in mantle-cell lymphoma. The differential expression of D-cyclin staining in two case examples of mantle-cell lymphoma is shown. Case 1 shows intense cyclin-D1 (a) and weak cyclin-D2 (b) staining. Case 2 shows weak cyclin-D1 (d) and strong cyclin-D2 (e) staining. Both cases lack staining for cyclin-D3 (c and f).

D-cyclins, the proliferation index ranged from 10 to $70 \%$. In low-grade lymphomas, no correlation was seen between the expression of D-cyclins, particularly cyclin-D2 and D3, and the degree of proliferation. For example, grade-1 follicular lymphomas with increased proliferation (three cases with $30 \%$ and one case with $80 \%$ Ki-67 positivity) did not express cyclin-D2 or D3. In high-grade lymphomas, including lymphoblastic lymphoma and subtypes of T-cell lymphoma with $>50 \%$ proliferation rate as measured by Ki-67, the proliferation index was highly correlated with expression of cyclin-D2 and D3: In B- and T-lymphoblastic lymphomas, 10/11 (90\%) cases expressed high levels of cyclin-D2 and three cases expressed high levels of cyclin-D3; the single case that expressed moderate amounts of cyclin-D2 showed high levels of cyclin-D3 expression. Similarly, the degree of proliferation in T-cell lymphoma subtypes was closely associated with increased levels of cyclinD2 expression: peripheral T-cell lymphoma 7/10 $(70 \%)$, ALCL $2 / 2(100 \%)$ and extranodal NK/T-cell lymphoma (nasal type) $2 / 2(100 \%)$. Six of the T-cell lymphomas also showed moderate expression of cyclin-D3.

\section{Discussion}

D-cyclins are cell-cycle-regulatory proteins whose expression and distribution in human tissue types and neoplasms are incompletely characterized. In the current work, we show that among the three D-cyclin proteins, cyclin-D1 has the most restricted 

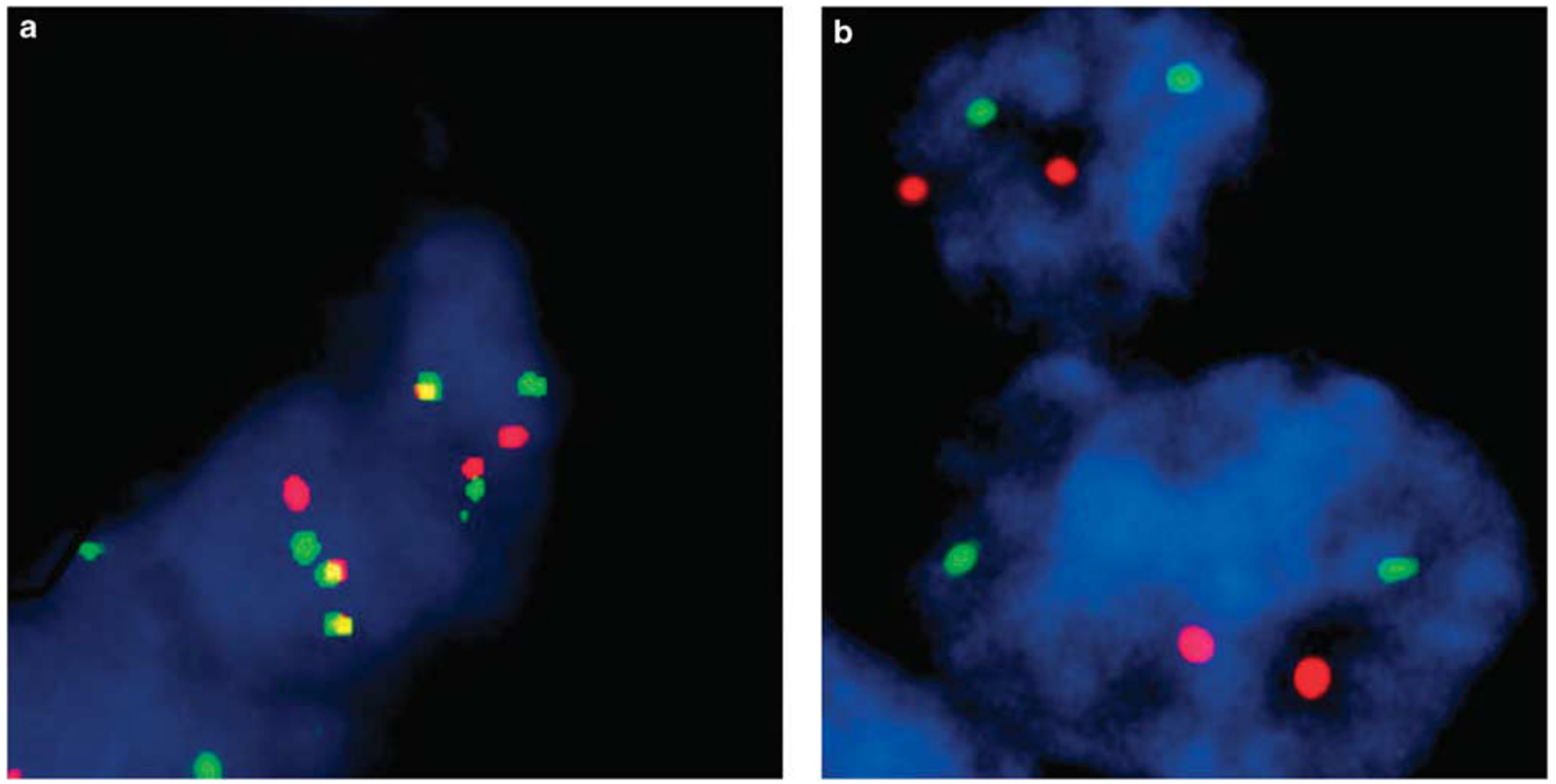

Figure 6 FISH for CCND1/IGH in mantle-cell and diffuse large B-cell lymphoma. An example of mantle-cell lymphoma shows the dual fusion signal associated with the CCND1/IGH translocation in numerous lymphoma cells (a). An example of cyclin-D1-positive diffuse large B-cell lymphoma shows no dual fusion signals within lymphoma cells, indicating the absence of the CCND1/IGH translocation (b).

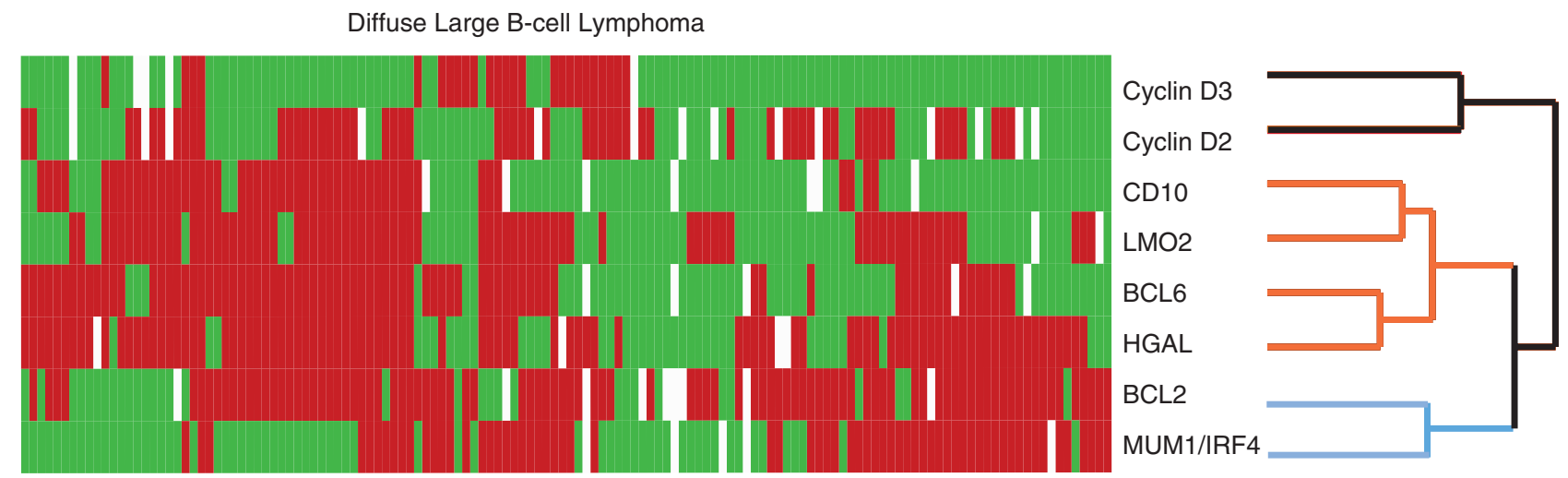

Figure 7 Hierarchical cluster analysis of immunohistological data from diffuse large B-cell lymphoma. Hierarchical cluster analysis shows that the expression profiles of cyclin-D2 and D3 proteins are similar to each other across the 143 cases of diffuse large B-cell lymphoma, but are distinct from that of the germinal-center-associated markers CD10, BCL6, HGAL and LMO2, and from the nongerminal-center markers BCL2 and MUM1/IRF4.

Table 3 Proliferation index (Ki-67) and expression of D-cyclins in diffuse large B-cell lymphomas

\begin{tabular}{lcrc}
\hline Proliferation index (Ki-67 staining) & Cyclin-D1 & Cyclin-D2 & Cyclin-D3 \\
\hline Low $(<30 \%)$ & $0 / 9(0 \%)$ & $6 / 9(66.6 \%)$ & $0 / 9(0 \%)$ \\
Intermediate $(30$ to $<50 \%)$ & $1 / 28(3.5 \%)$ & $16 / 28(57.1 \%)$ & $2 / 28(7.1 \%)$ \\
High $(>50 \%)$ & $0 / 24(0 \%)$ & $15 / 24(62.5 \%)$ & $4 / 24(16.6 \%)$
\end{tabular}

pattern of expression, whereas cyclin-D2 exhibits more widespread expression in a variety of hematopoietic and non-hematopoietic tissues. The expression pattern of cyclin-D2 and D3 is in sharp contrast to the known tissue distribution of cyclinD1, which is not found in normal hematopoietic cells. Our findings are in keeping with studies of mouse splenic B-cells that showed cyclin-D2 and 
D3, but not D1, as crucial for the proliferative capacity of mitogen stimulation of B-cells. ${ }^{19}$ In normal hematopoietic tissues, cyclin-D2 and D3 were expressed in a proportion of B- and T-cell subsets as ascertained by double-labeling experiments. Although cyclin-D3 was found in fewer lymphoid cells than cyclin-D2, the pattern of expression in different lymphoid-cell compartments in normal hematopoietic organs (tonsil, lymph node, thymus and spleen) was similar to each other. Most importantly, a significant proportion of germinal-center B-cells lacked cyclin-D2 and D3 staining. Although cyclin-D2 is essential for B-cell-receptormediated signaling and proliferation of naïve $\mathrm{B}$-cells, ${ }^{20,21}$ its low abundance in germinal-center B-cells is supported by prior gene expression profiling studies. ${ }^{22}$ The mechanism by which germinal-center B-cells proliferate in the absence of these key cell-cycle regulators of the $\mathrm{G}_{1} / \mathrm{S}$ transition that controls cell proliferation, is as yet unknown.

The expression of cyclin-D2 and D3 proteins in normal hematopoietic tissues was mirrored by their expression across the hematopoietic neoplasms studied, with some exceptions. Cyclin-D2 was the most widely expressed D-cyclin and was found in almost all subtypes of lymphomas, including a subset of classical Hodgkin lymphoma. Although normal myeloid precursors and blasts in the bone marrow did not show significant amount of staining for cyclin-D2, all acute myeloid leukemias and subsets of B- and T-lymphoblastic lymphoma/leukemias showed staining for cyclin-D2 in a subset of blasts. Cyclin-D3 staining was detected in erythroid precursors and in megakaryocytes in the normal bone marrow, and its overexpression was also detected in a subset of the blasts in all acute myeloid leukemias and in B- and T-lymphoblastic lymphoma/leukemias. Given that cyclin-D2 and D3 expression is minimal or absent in normal marrow precursors, these findings raise the possibility that their expression may be activated during leukemogenesis and are overexpressed in acute leukemias. Since a significant proportion of acute leukemias showed overexpression of both cyclin-D2 and D3, these results suggest the possibility of coordinate regulation of cyclin-D2 and D3 in these leukemias.

Translocation $t(11 ; 14)(q 13 ; q 32)$ at the cyclin-D1 locus results in the overexpression of the cyclin-D1 protein, which accelerates lymphoma cells through the $G_{1} / S$ transition of the cell cycle, leading to dysregulated proliferation..$^{5,6}$ In cyclin-D1-negative mantle-cell lymphomas, there is overexpression of cyclin-D2 or D3 proteins. ${ }^{7}$ Furthermore, knockdown of cyclin-D1 mRNA in mantle-cell lymphoma cell lines have shown a modest compensatory increase in the expression of cyclin-D2 mRNA and protein, suggesting the possibility for coordinate regulation of the expression of D-cyclins. ${ }^{23}$ This finding is in keeping with gene-targeting experiments on mice deficient in D-cyclins that suggested the presence of functional redundancy among mammalian
D-cyclins. ${ }^{24}$ Several recent reports have described translocations targeting the $C C N D 2$ or $C C N D 3$ loci in cyclin-D1-negative mantle-cell lymphomas: $\mathrm{t}(12 ; 14)$ (p13;q32)/IGH-CCND2, t (2;12)(p11;p13)/IGK-CCND2 and $\mathrm{t}(6 ; 14)(\mathrm{p} 21 ; \mathrm{q} 32) / I G H-C C N D 3 .^{8-10}$ We performed FISH analysis to further interrogate our cohort of mantle-cell lymphoma cases: 16/18 cases harbored the $C C N D 1 / I G H$ translocation and all expressed the cyclin-D1 protein. The single case in our series that showed weak cyclin-D1 but strong cyclin-D2 staining was found to harbor the CCND1/IGH translocation. Therefore, we did not pursue additional cytogenetic analyses as our cases would be unlikely to yield a known or novel translocation involving CCND2 or CCND3. However, it would be of interest to characterize the cytogenetic abnormalities of additional cyclin-D1-negative mantle-cell lymphomas to better understand the spectrum of chromosomal defects acquired by this rare type of lymphoma.

Apart from mantle-cell lymphoma, cyclin-D1 expression was detected in four cases $(2 \%)$ of diffuse large B-cell lymphoma. These cases showed intense nuclear staining in the vast majority of lymphoma cells. In two cases where material was available for cytogenetic/FISH studies, neither the CCND1/IGH translocation nor abnormalities associated with the CCND1 locus was detected. Complete karyotypic analysis was not performed due to lack of fresh tissue. Rare cases of cyclin-D1-positive diffuse large B-cell lymphoma have been reported previously. ${ }^{25,26}$ In a series of 231 cases of diffuse large B-cell lymphoma, Ehinger et a ${ }^{25}$ described 10 cases $(4 \%)$ that showed staining for cyclin-D1; the majority of these cases showed aberrances involving the CCND1 locus and one case showed the CCND1/ IGH translocation. In a single case reported by Rodriguez-Justo et $a{ }^{26}{ }^{26}$ aberrances involving the CCND1 locus, but not the translocation, were detected. Our findings are in keeping with these prior observations that cyclin-D1 is expressed in rare cases of diffuse large B-cell lymphoma. These findings underscore the importance of using an integrated approach to diagnosis that involves morphological assessment, clinical input and a panel of immunostains (including BCL2, BCL6, IgM and IgD in addition to cyclin-D1) to distinguish among large-cell or blastoid variants of mantle-cell and diffuse large B-cell or other high-grade B-cell lymphomas.

Our results from a variety of lymphoma subtypes show that immunostaining for cyclin-D2 and D3 lacks specificity with regards to a particular subtype of lymphoma; staining for cyclin-D2 and D3 was found in a subset of almost all types of B- and T-cell lymphomas, including lymphoblastic and classical Hodgkin lymphomas. As important cell-cycle-regulatory molecules, the overexpression of cyclin-D2 and D3 proteins in lymphomas and leukemias with a propensity for increased proliferation is not unexpected. This is reflected in our data on 
lymphoblastic lymphoma and T- and NK-cell lymphoma subtypes where all cases that showed high degree of proliferation ( $>50 \%$ by Ki-67 staining) also showed high levels of expression of cyclin-D2 and/or D3. Of particular interest is that a significant proportion of low-grade B-cell lymphomas also express cyclin-D2 and D3. In these cases, the expression of D-cyclins did not correlate with increased proliferation. This finding is particularly relevant to grade-1 follicular lymphomas with increased proliferation, a group of lymphomas reported to follow a more aggressive clinical course. ${ }^{27}$ The four cases in our cohort that belong to this category showed no expression of D-cyclin proteins. These findings may be suggestive of additional as yet unidentified cyclins that may be involved in the regulation of proliferation in lymphoma subtypes or other mechanisms of cellcycle regulation at play. Therefore, it should be emphasized that the presence of cyclin-D2 or D3 staining in a low grade B-cell lymphoma should not be interpreted as compatible with a diagnosis of cyclin-D1-negative mantle-cell lymphoma. This latter entity is a rare diagnosis and as such, morphological features, other immunohistological markers (CD5, IgM and IgD) and FISH studies for abnormalities involving the CCND1 locus should be correlated before diagnosis of this rare entity is rendered. In addition, since cyclin-D2 and D3 proteins are expressed in lymphoid and myeloid leukemias, caution should be exercised in using these stains for bone marrow diagnosis. Potential pitfalls include cases in which the marrow is replaced by a diffuse proliferation of intermediate cell size where a concurrent aspirate smear is not available for sufficient morphological assessment; this proliferation could potentially lead to confusion of a lymphoblastic or myeloid leukemia with mantlecell lymphoma. Therefore, given the expression of cyclin-D2 and D3 in a variety of lymphoid subtypes, it is necessary for careful assessment of these markers in the context of other findings.

The overexpression of cyclin-D2 and D3 proteins in a variety of subsets of lymphomas raises the possibility that dysregulation of specific biological pathways associated with the cell cycle may play a role in their pathogenesis and prognosis. For example, we found that among ALK-positive ALCLs, $60 \%$ overexpressed cyclin-D2 and 25\% overexpressed cyclin-D3. This result corresponds with previous gene expression profiling studies that identified the expression of cyclin-D3 in ALKpositive but not in ALK-negative ALCLs. ${ }^{28}$ These findings further suggest that ALK-positive ALCL may exploit a different mechanism of promoting $G_{1} /$ $S$ transition than its ALK-negative counterpart. Given the significant difference in clinical outcome between these entities, the overexpression of cyclinD3 may prove to be a marker of superior outcome in this disease. However, further work on sufficiently well-characterized ALK-positive and ALK-negative
ALCL cases is needed to formally prove this hypothesis.

We previously identified CCND2 as the best predictor of inferior survival in diffuse large B-cell lymphoma patients in a multivariate model based on the expression of six genes as measured by quantitative RT-PCR. ${ }^{11,12}$ Immunohistochemical staining for cyclin-D2 was also found to be associated with inferior outcome in patients with diffuse large B-cell lymphoma treated with anthracyclinecontaining chemotherapy. ${ }^{13}$ In a set of 143 cases of diffuse large B-cell lymphoma that we have previously evaluated for markers of germinal-center and non-germinal-center derivation, ${ }^{15,16,18,29}$ hierarchical cluster analysis showed that cyclin-D2 and D3 staining exhibits protein expression profiles that are similar to each other across the diffuse large B-cell lymphoma cases. This pattern of expression of cyclin-D2 and D3 in diffuse large B-cell lymphoma suggests that the relationship of these proteins to prognostic stratification may be associated with cellcycle control rather than the cell of origin. However, in our cohort of diffuse large B-cell lymphoma cases, the degree of proliferation as measured by Ki-67 staining and the expression of D-cyclins did not yield a significant correlation. In addition, cases that did not express any of the three D-cyclins showed a range of proliferation from 10 to $70 \%$. Therefore, the proliferative capacity of diffuse large B-cell lymphomas is likely governed by complex and as yet unknown mechanisms that may not be restricted to cell-cycle control. Of note, prior gene expression profiling studies showed low abundance of cyclinD2 in germinal-center B-cells, ${ }^{22}$ although our data shows variable expression of cyclin-D2 protein in germinal-center B-cells. Our findings also differ from a previous report that found that cyclin-D3 but not cyclin-D2 was expressed in germinal-center B-cells. ${ }^{30}$ Whether the differential expression of cyclin-D2 and D3 proteins is associated with patient outcome, warrants further investigation in a cohort of diffuse large B-cell lymphoma patients uniformly treated with rituximab-based immunochemotherapy, as these regimens have been shown to be of improved benefit for patients with diffuse large Bcell lymphoma. ${ }^{31-34}$

\section{Acknowledgement}

We thank Edward Gilbert for technical assistance with immunohistochemistry and Thelma Santa Maria for administrative support. Grant support: NIH CA34233, NIH CA109335 and the Dwoskin Family Foundation.

\section{Disclosures/conflict of interest}

The authors declare no conflict of interest. 


\section{References}

1 Malumbres M, Barbacid M. Cell cycle, CDKs and cancer: a changing paradigm. Nat Rev Cancer 2009;9:153-166.

2 Malumbres M, Sotillo R, Santamaria D, et al. Mammalian cells cycle without the D-type cyclin-dependent kinases Cdk4 and Cdk6. Cell 2004;118:493-504.

3 Sherr CJ. G1 phase progression: cycling on cue. Cell 1994;79:551-555.

4 Suzuki R, Kuroda H, Komatsu H, et al. Selective usage of D-type cyclins in lymphoid malignancies. Leukemia 1999;13:1335-1342.

5 Rosenberg CL, Wong E, Petty EM, et al. PRAD1, a candidate BCL1 oncogene: mapping and expression in centrocytic lymphoma. Proc Natl Acad Sci USA 1991;88:9638-9642.

6 Swerdlow SH, Campo E, Harris NL, et al. WHO Classification of Tumours of Haematopoietic and Lymphoid Tissues. IARC: Lyon, 2008.

7 Fu K, Weisenburger DD, Greiner TC, et al. Cyclin D1negative mantle cell lymphoma: a clinicopathologic study based on gene expression profiling. Blood 2005;106:4315-4321.

8 Gesk S, Klapper W, Martin-Subero JI, et al. A chromosomal translocation in cyclin D1-negative/ cyclin D2-positive mantle cell lymphoma fuses the CCND2 gene to the IGK locus. Blood 2006;108:11091110.

9 Herens C, Lambert F, Quintanilla-Martinez L, et al. Cyclin D1-negative mantle cell lymphoma with cryptic $\mathrm{t}(12 ; 14)(\mathrm{p} 13 ; \mathrm{q} 32)$ and cyclin D2 overexpression. Blood 2008;111:1745-1746.

10 Wlodarska I, Dierickx D, Vanhentenrijk V, et al. Translocations targeting CCND2, CCND3, and MYCN do occur in t(11;14)-negative mantle cell lymphomas. Blood 2008;111:5683-5690.

11 Lossos IS, Czerwinski DK, Alizadeh AA, et al. Prediction of survival in diffuse large-B-cell lymphoma based on the expression of six genes. N Engl J Med 2004;350:1828-1837.

12 Malumbres R, Chen J, Tibshirani R, et al. Paraffinbased 6-gene model predicts outcome in diffuse large B-cell lymphoma patients treated with R-CHOP. Blood 2008;111:5509-5514.

13 Hans CP, Weisenburger DD, Greiner TC, et al. Expression of PKC-beta or cyclin D2 predicts for inferior survival in diffuse large B-cell lymphoma. Mod Pathol 2005;18:1377-1384.

14 Moller MB, Nielsen O, Pedersen NT. Cyclin D3 expression in non-Hodgkin lymphoma. Correlation with other cell cycle regulators and clinical features. Am J Clin Pathol 2001;115:404-412.

15 Natkunam Y, Lossos IS, Taidi B, et al. Expression of the human germinal center-associated lymphoma (HGAL) protein, a new marker of germinal center B-cell derivation. Blood 2005;105:3979-3986.

16 Natkunam Y, Warnke RA, Montgomery $\mathrm{K}$, et al. Analysis of MUM1/IRF4 protein expression using tissue microarrays and immunohistochemistry. Mod Pathol 2001;14:686-694.

17 Marinelli RJ, Montgomery K, Liu CL, et al. The stanford tissue microarray database. Nucleic Acids Res 2008;36:D871-D877.

18 Natkunam Y, Zhao S, Mason DY, et al. The oncoprotein LMO2 is expressed in normal germinal-center B cells and in human B-cell lymphomas. Blood 2007;109: $1636-1642$.

19 Su TT, Rawlings DJ. Transitional B lymphocyte subsets operate as distinct checkpoints in murine splenic B cell development. J Immunol 2002;168:2101-2110.

20 Solvason N, Wu WW, Parry D, et al. Cyclin D2 is essential for BCR-mediated proliferation and CD5 B cell development. Int Immunol 2000;12:631-638.

21 Jena N, Deng M, Sicinska E, et al. Critical role for cyclin D2 in BCR/ABL-induced proliferation of hematopoietic cells. Cancer Res 2002;62:535-541.

22 Alizadeh AA, Eisen MB, Davis RE, et al. Distinct types of diffuse large B-cell lymphoma identified by gene expression profiling. Nature 2000;403: 503-511.

23 Klier M, Anastasov N, Hermann A, et al. Specific lentiviral shRNA-mediated knockdown of cyclin D1 in mantle cell lymphoma has minimal effects on cell survival and reveals a regulatory circuit with cyclin D2. Leukemia 2008;22:2097-2105.

24 Chiles TC. Regulation and function of cyclin D2 in B lymphocyte subsets. J Immunol 2004;173:2901-2907.

25 Ehinger M, Linderoth J, Christensson B, et al. A subset of CD5- diffuse large B-cell lymphomas expresses nuclear cyclin D1 with aberrations at the CCND1 locus. Am J Clin Pathol 2008;129:630-638.

26 Rodriguez-Justo M, Huang Y, Ye H, et al. Cyclin D1positive diffuse large B-cell lymphoma. Histopathology 2008;52:900-903.

27 Wang SA, Wang L, Hochberg EP, et al. Low histologic grade follicular lymphoma with high proliferation index: morphologic and clinical features. Am J Surg Pathol 2005;29:1490-1496.

28 Thompson MA, Stumph J, Henrickson SE, et al. Differential gene expression in anaplastic lymphoma kinase-positive and anaplastic lymphoma kinase-negative anaplastic large cell lymphomas. Hum Pathol 2005;36:494-504.

29 Natkunam Y, Farinha P, Hsi ED, et al. LMO2 protein expression predicts survival in patients with diffuse large B-cell lymphoma treated with anthracyclinebased chemotherapy with and without rituximab. J Clin Oncol 2008;26:447-454.

30 Teramoto N, Pokrovskaja K, Szekely L, et al. Expression of cyclin D2 and D3 in lymphoid lesions. Int J Cancer 1999;81:543-550.

31 Sehn LH, Donaldson J, Chhanabhai M, et al. Introduction of combined CHOP plus rituximab therapy dramatically improved outcome of diffuse large B-cell lymphoma in British Columbia. J Clin Oncol 2005;23:5027-5033.

32 Coiffier B, Lepage E, Briere J, et al. CHOP chemotherapy plus rituximab compared with CHOP alone in elderly patients with diffuse large-B-cell lymphoma. N Engl J Med 2002;346:235-242.

33 Habermann TM, Weller EA, Morrison VA, et al. Rituximab-CHOP versus CHOP alone or with maintenance rituximab in older patients with diffuse large B-cell lymphoma. J Clin Oncol 2006;24:3121-3127.

34 Pfreundschuh $\mathrm{M}$, Trumper L, Osterborg A, et al. CHOP-like chemotherapy plus rituximab versus CHOP-like chemotherapy alone in young patients with good-prognosis diffuse large-B-cell lymphoma: a randomised controlled trial by the MabThera International Trial (MInT) Group. Lancet Oncol 2006; 7:379-391. 